\title{
A Melhor Esquina do País: as práticas empreendedoras dos agentes estatais na PPP Nova Cidade Albor ${ }^{1}$
}

\section{The Best Corner of the Country: the entrepreneurial practices of state agents in PPP Nova Cidade Albor}

\author{
Garcia, Aldo'; Bernardini, Sidney² \\ 1 UNICAMP, FEC, Campinas, Brasil aldogarcia.arq@gmail.com \\ 2 UNICAMP, sidpiochi@fec.unicamp.br
}

\begin{abstract}
RESUMO
O artigo a seguir procurou analisar e demonstrar possíveis contradições e inconsistências na elaboração da proposta da Parceria público privada (PPP) Nova Cidade Albor, lançada em 2017, pela CDHU. A PPP se insere no âmbito do Programa de PPP Habitacional da Casa Paulista do Governo do Estado de São Paulo, lançado em 2011. Reconhecendo o grau de vulnerabilidade da região, procurou-se através das abordagens realizadas avaliar as relações entre os principais agentes envolvidos nos direcionamentos e diretrizes do empreendimento. Foram levantados questionamentos quanto às contradições encontradas na leitura da estrutura legal e contextual que regulamenta a PPP e nos textos do Edital. O artigo procurou mostrar como o Governo do Estado abre mão dos processos participativos de planejamento ao criar os meios necessários para realização do empreendimento de acordo com interesses do mercado imobiliário.
\end{abstract}

Palavras-chave: parceria público-privada, Habitação de interesse social, urbanização.

\begin{abstract}
The following article sought to analyze and demonstrate possible contradictions and inconsistencies in the preparation of the New Public Alboration (PPP) proposal New City Albor, launched in 2017, by the CDHU. The PPP is part of the PPP Housing Program of the Government of the State of São Paulo, launched in 2011 . Recognizing the degree of vulnerability of the region, it was sought through the approaches carried out to evaluate the relationship between the main agents involved in the directives and guidelines of the enterprise. Questions were raised regarding the contradictions found in reading the legal and contextual structure that regulates the PPP and in the texts of the Notice. The article sought to show how the State Government gives up participatory planning processes by creating the necessary means to carry out the project in accordance with the interests of sectors related to the real estate market.
\end{abstract}

Keywords: public-private partnership, Housing, urbanization.

\footnotetext{
${ }^{1}$ GARCIA, Aldo; BERNARDNI, Sidney. A Melhor Esquina do País: as práticas empreendedoras dos agentes estatais na PPP Nova Cidade Albor. In: II SIMPÓSIO NACIONAL DE GESTÃO E ENGENHARIA URBANA: SINGEURB, 2019, São Paulo. Anais... Porto Alegre: ANTAC, 2019.
} 


\section{INTRODUÇÃO}

Os processos de financeirização observados nas últimas décadas sinalizam para supremacia da extração de renda sobre o capital produtivo, mantendo estreitas relações com o circuito imobiliário (HARVEY, 2016). Neste contexto, a urbanização vem a reboque do crescimento econômico com a possibilidade de expansão e criação de centralidades, constituindo novas áreas para exploração. Desta forma, os governos desenvolveram capacidades de mediação, negociação e mobilização por meio da reorganização institucional e regulatória, atuando como parceiros do mercado (WEBER, 2010). Segundo O'brien et al. (2018; 2019), o discurso das políticas públicas contemporâneas está encorajando a canalização de investimento em infraestrutura pública e privada para apoiar o crescimento ou alavancar setores em crise (O'BRIEN et al. 2018).

No Brasil, o início desta transformação ocorre mais intensamente nos anos 1990 com a abertura econômica e o avanço de políticas neoliberais. Porém, o arcabouço legal que nos interessa caracteriza-se pela Lei de Concessões de 1995 e, principalmente, pela instituição das Parcerias Público Privada (PPP) em 2004, onde a contraprestação paga ao setor privado resolveu o impasse existente quanto à execução de serviços subsidiados pelo Estado. As concessões, antes voltadas a obras de infraestrutura agora encontram novos setores para exploração e privatização, incluindo habitação de interesse social. Este contexto possibilitou em 2011, no Estado de São Paulo, a estruturação das PPP's Habitacionais. A proposta divulgada como inovadora pelo Secretário de Habitação tinha como objetivo a construção, financiamento e gestão de 50 mil moradias em regiões estratégicas, totalizando $R \$ 7,3$ bilhões em investimentos privados.

A partir destes fatores, o artigo pretende abordar os métodos utilizados pelo Estado na elaboração da proposta da PPP Nova Cidade Albor, lançada em 2017. Por meio deste estudo de caso pretende-se avaliar se a proposta e o discurso dos principais agentes estatais envolvidos na elaboração da PPP estão alinhados ao contexto de transformação do estado acima mencionado. Por se tratar de um empreendimento complexo e de grande escala, procurou-se avaliar se as precariedades apresentadas no entorno foram levadas em consideração durante a elaboração da proposta. A discussão foi estruturada por meio de consultas em documentos e publicações oficiais, como: Diário Oficial do Governo do Estado (DOE); Editais; Contratos e Convênios. A consulta a legislação municipal também foi necessária através da análise dos Zoneamentos e Planos Diretores dos municípios. Para avaliar a precariedade dos bairros do entorno foram utilizados dados extraídos do Censo 2010; PNAD 2015 e IPVS. A análise do discurso dos principais agentes envolvidos na elaboração da proposta foi baseada na consulta de matérias jornalísticas e declarações e notas oficiais. Tendo isso em mente, o artigo apresenta caráter indutivo através de uma análise empírica, onde se buscou por meio de uma abordagem crítica em que o campo de investigação é delineado por um estudo de caso, exemplificar como a atuação dos agentes estatais se encaixam numa dinâmica global de transformação das antigas formas de administração.

\section{A MELHOR ESQUINA DO PAÍ́2}

A PPP Nova Cidade Albor se torna interessante pelas relações entre os agentes envolvidos nas arenas decisórias e na transformação do papel do Estado, evidenciada pela proposta do PUBr (Plano Urbanístico Básico de referência) e nos dados quantitativos do Edital. A área destinada ao empreendimento possui 1,7 milhões de $\mathrm{m}^{2}$, nos limites dos municípios de Arujá, Itaquaquecetuba e Guarulhos, entre a Rodovia Presidente Dutra e Ayrton Senna, sendo cortado pelo trecho leste do Rodoanel. O Edital lançado em abril, foi republicado em julho de 2017 (DOE 08/07/2017), pois as empresas interessadas na concorrência solicitaram mudanças e a Secretaria da Habitação decidiu adotá-las para aumentar o número de concorrentes ampliando a competitividade da licitação. O total de moradias aumentou de 10 mil unidades

2 O título do artigo "A melhor esquina do país" ironiza as práticas empreendedoras de marketing da CDHU e Governo do Estado, em matéria publicada no jornal O Estado de São Paulo (2017), na tentativa de tornar a proposta da PPP Nova Cidade Albor atrativa ao setor imobiliário através da acessibilidade proporcionada pela terra destinada ao empreendimento. 
para 13.100, sendo 10.480 de HIS (Habitação de Interesse Social) e 2.620 de HMP (Habitação de Mercado Popular). Além das moradias, o projeto previa a exploração econômica através da instalação de indústrias leves, áreas de comércio e de um condomínio logístico. Quanto aos valores, a somatória dos investimentos a serem realizados pela Concessionária é de aproximadamente $R \$ 2,22$ bilhões. O valor da contraprestação anval máxima a ser paga pelo estado será de no máximo $R \$ 43,9$ milhões, composta pelos valores mensais da contraprestação pecuniária. A Concessionária está autorizada a explorar Receitas Acessórias decorrentes de alienação ou da realização de atividades em espaços não habitacionais. A taxa de retorno do investidor está prevista para 9,7\%.

Figura 1 - Localização do Empreendimento.

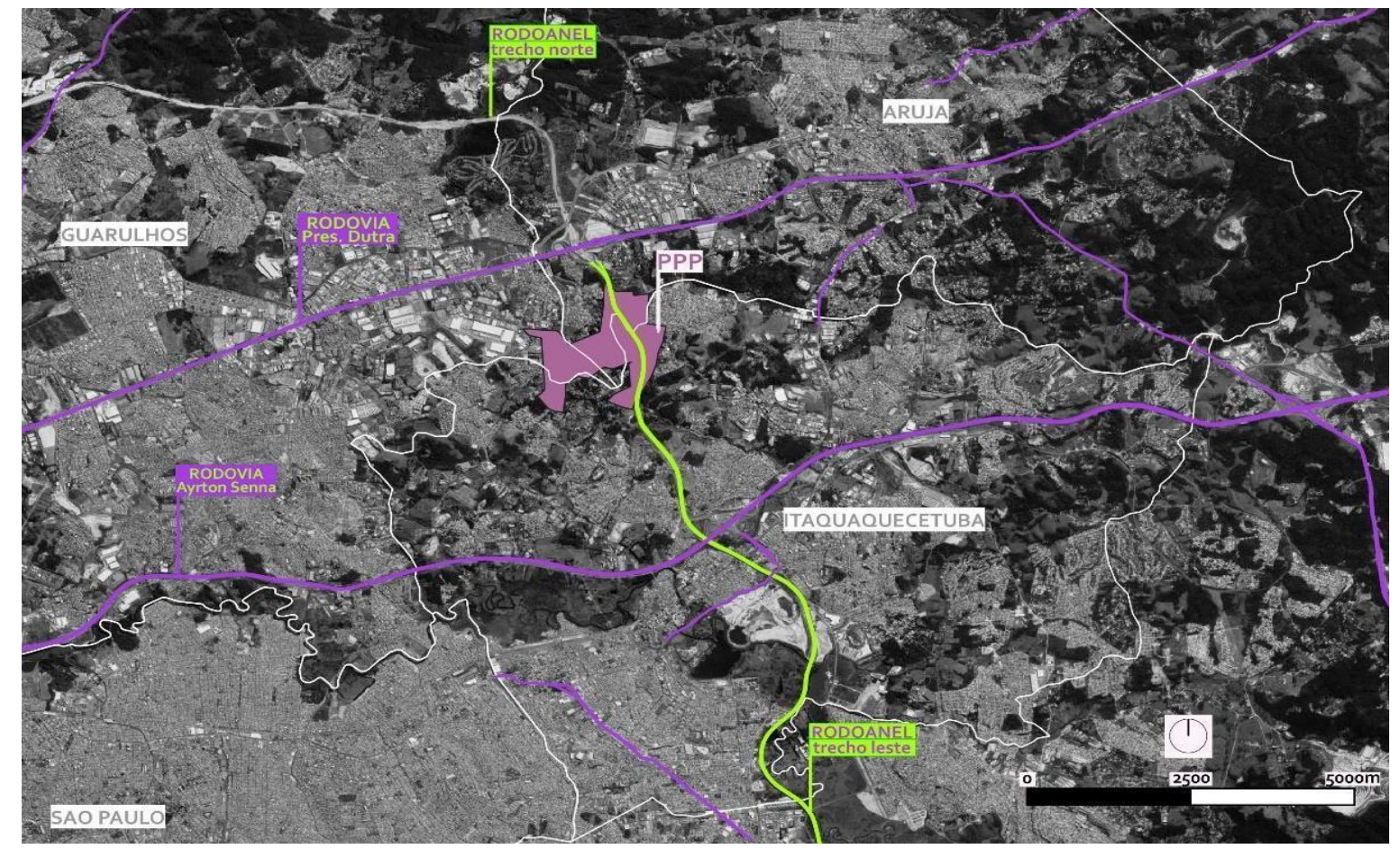

Fonte: Secretaria de Habitação do Governo do Estado de São Paulo. Elaborado pelos autores. (2018)

Tabela 1 - Áreas e número de unidades habitacionais (UH) por município.

\begin{tabular}{ccccc}
\hline Áreas $\left(\mathbf{m}^{2}\right) / \mathbf{U H}$ & Arujá & Guarulhos & Itaquaquecetuba & Total \\
\hline Espaço Público & 2.099 & - & 24.367 & $\mathbf{2 6 . 4 6 6}$ \\
Institucional & 36.389 & 24.263 & 22.264 & $\mathbf{8 2 . 9 1 6}$ \\
Habitacional & 262.879 & 13.085 & 189.745 & $\mathbf{4 6 5 . 7 0 9}$ \\
Comercial & 42.211 & 6.931 & 27.141 & $\mathbf{7 6 . 2 8 3}$ \\
Logística/industrial & - & 206.939 & - & $\mathbf{2 0 6 . 9 3 9}$ \\
Sistema Viário & 115.631 & 58.478 & 68.416 & $\mathbf{2 4 2 . 5 2 5}$ \\
Áreas Verdes & 188.640 & 148.442 & 193.206 & $\mathbf{3 4 1 . 6 4 8}$ \\
Total no PUB(m $\left.{ }^{2}\right)$ & $\mathbf{6 4 8 . 0 5 0}$ & $\mathbf{4 5 8 . 1 3 7}$ & $\mathbf{5 2 5 . 1 3 8}$ & $\mathbf{1 . 6 2 8 . 4 6 4}$ \\
\hline Quantidade HIS(UH) & 6.270 & 250 & 3.960 & $\mathbf{1 0 . 4 8 0}$ \\
$\%$ & $60 \%$ & $2 \%$ & $38 \%$ & $\mathbf{1 0 0 \%}$ \\
Quantidade HMP (UH) & 1.530 & 100 & 990 & $\mathbf{2 . 6 2 0}$ \\
$\%$ & $58 \%$ & $4 \%$ & $38 \%$ & $\mathbf{1 0 0 \%}$ \\
Total Unidades (UH) & $\mathbf{7 . 8 0 0}$ & $\mathbf{3 5 0}$ & $\mathbf{4 . 9 5 0}$ & $\mathbf{1 3 . 1 0 0}$ \\
\% & $\mathbf{5 9 \%}$ & $\mathbf{3 \%}$ & $\mathbf{3 8 \%}$ & $\mathbf{1 0 0 \%}$ \\
\hline
\end{tabular}

Fonte: Secretaria de Habitação do Estado de São Paulo,2018. Os autores.

As isenções constituem outro aspecto que deve ser abordado. Antes mesmo do edital ir para 
Consulta a partir da reunião da CGPPP em 23/08/2016 (DOE 09/09/2016), colocava-se em pauta a possibilidade de se obter dos governos municipais isenção ou redução de alíquota do ISS (Imposto sobre Serviços de Qualquer Natureza) incidente sobre o projeto. No final do mesmo ano, em 06-12-2016 (DOE 14/01/2017), o ex-Secretário de Habitação do Estado novamente destacou a importância do diálogo com as Prefeituras para avançar na questão relacionada à eventual isenção de ISS. Após o Edital ser lançado, o Contrato de Convênio entre Estado e Município, na Cláusula Segunda, é demandado que se "Viabilize a isenção de taxas e demais ônus incidentes sobre os projetos do empreendimento e às unidades habitacionais e não habitacionais a ele vinculados; e que se viabilize a isenção tributária de ISS incidente sobre todas as obras e serviços necessários à implantação da PPP." As isenções, o zoneamento industrial e o condomínio logístico exclusivamente em Guarulhos, contribuíram para a mudança de comportamento das prefeituras de Arujá e Itaquaquecetuba no decorrer das discussões. Anseiam, por isso, pelos investimentos do setor privado no seu território, tanto no que se refere à receita quanto à geração de empregos. Para o prefeito arujaense José Luiz Monteiro (2017), o aumento populacional que a PPP traria para o município é desproporcional (uma demanda equivalente a $36 \%$ da população atual), mal planejado e acarretaria problemas sociais e de infraestrutura irreversíveis.

Figura 2 - Vulnerabilidade Social do entorno.

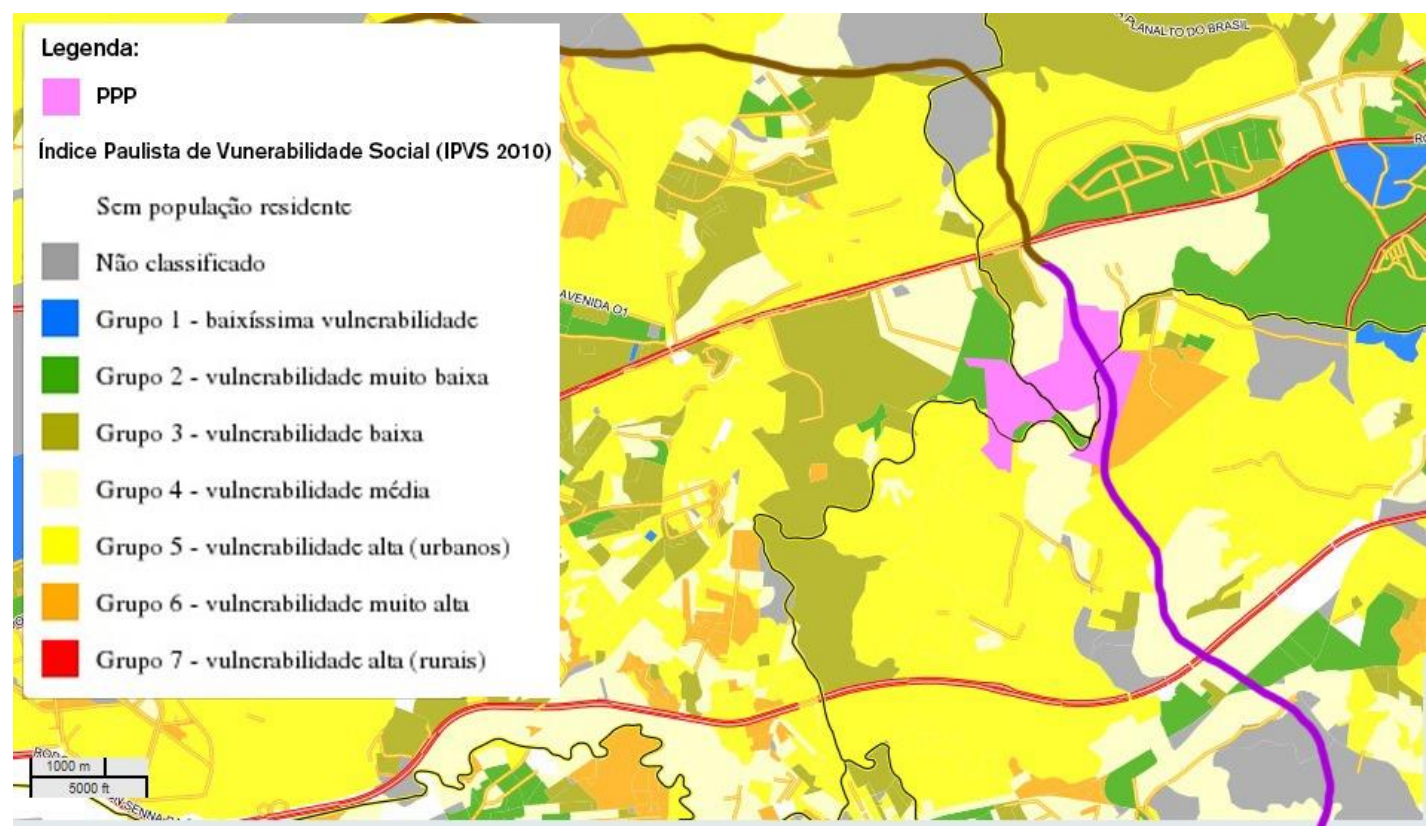

Fonte: IPVS (2010). Elaborado pelos autores em http://datageo.ambiente.sp.gov.br. (2018)

A produção de moradia é necessária e, de fato, é louvável que políticas destinadas a atender esta demanda estejam sendo elaboradas, porém, o que se coloca em questão é a implantação de um empreendimento desta escala nas margens da região metropolitana em meio a localidades que já apresentam alto índice de precariedade. O empreendimento encontra-se cercado por bairros avaliados como Alta ou Muito Alta Vulnerabilidade segundo o Índice Paulista de Vulnerabilidade Social (IPVS 2010), apresentando um rendimento familiar baixo de 1,5 salário mínimo em valores corrigidos (PNAD 2015). Além disso, o terreno é de propriedade da CDHU desde 1997 e somente em maio de 2017 foi destinado a um uso. Durante esse tempo, a terra acarretou custos ao estado nos processos de reintegração de posse. Inserida numa área precária e carente de infraestrutura, tornou-se alvo de ocupações no decorrer dos anos. No último episódio, em agosto de 2015, 550 policiais executaram a tarefa de reintegração de posse da terra a pedido da CDHU. No dia, havia apenas 300 famílias no local. Entretanto, o líder da ocupação Rafael do Nascimento (G1 Mogi das Cruzes, 2015), afirma que ali moravam quase 3 mil famílias que se retiraram gradativamente durante as semanas que antecederam a reintegração de posse, com o objetivo de evitar conflitos. 
Figura 3 - Reintegração de posse e queima de moradias na área ocupada.

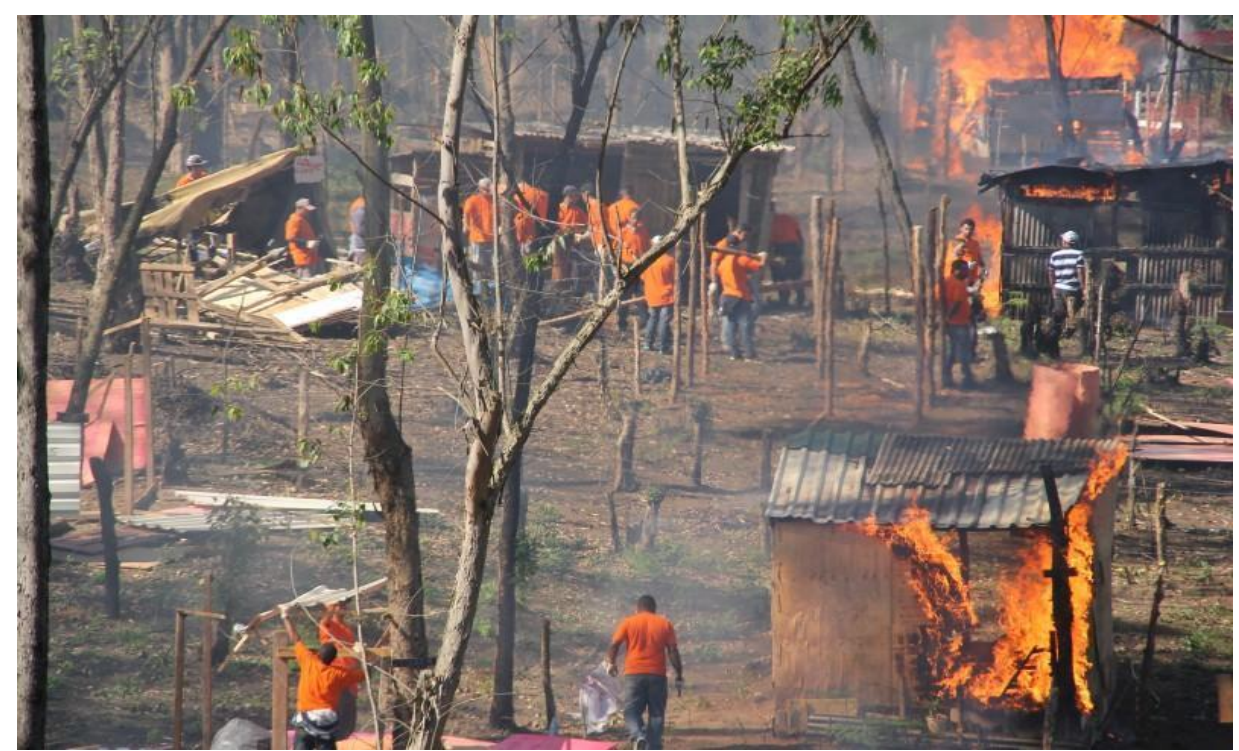

Fonte: Mogi News (2015)

\section{CONCLUSÕES}

Ao final do pleito, o fato do Edital não ter recebido manifestações de interesse destaca o fracasso da PPP Habitacional que, em 2017, havia entregue $1 \%$ das 50 mil unidades prometidas (EXAME, 2017), resultado atribuído ao cenário econômico atual. Na reunião da CGPPP, no dia 27/03/2018(DOE 12/04/2018) foram divulgados os valores de ressarcimento para os estudos aproveitados no desenvolvimento da modelagem: à MRV/Andrade Gutierrez o valor de $\mathrm{R} \$$ 694.548,00 (pelo aproveitamento de 23,6\% dos estudos); e à Tenda/Alphaville o valor de $\mathrm{R} \$ 671.004,00$ (pelo aproveitamento de 22,8\%). Com isso, a Secretaria de Habitação gastou quase 1,4 milhão em estudos para uma licitação que não obteve nenhum resultado. A proposta não foi atrativa ao mercado imobiliário, mesmo com praticamente metade da proposta sendo elaborada de acordo com interesses do setor e com as terras fornecidas pela CDHU. Os mecanismos e garantias do estado se mostraram insuficientes para reaquecer 0 setor que, mesmo em crise, não achou o retorno de 9,7\% satisfatório. Em todo processo de elaboração foram realizadas apenas uma Audiência Pública e uma consulta pública que consistiu no acesso aos editais e contratos disponibilizados no site. Portanto, o Governo do Estado entende participação popular como liberar acesso a materiais e documentos, o que nada mais é do que a obrigação de um processo licitatório, enquanto desconsidera a participação dos municípios e da população na elaboração da proposta.

Desta forma, pode-se afirmar que a terra onde está localizada a PPP realmente é "a melhor esquina do país", já que se trata de um vetor de urbanização em processo de expansão localizada entre as mais importantes rodovias que dão acesso à capital. Mas as potencialidades que tornam a 'esquina' tão encantadora interessam bem mais ao setor logístico e imobiliário do que aos futuros moradores, ou aos que moram nos bairros precários do entorno. O Governo do Estado torna-se mediador do processo ao comprometer terras públicas e criar as frentes de expansão necessárias para os investimentos em setores supracitados, sem realizar devidamente os processos de participação popular. Enquanto isso, Prefeituras competem entre si para que as indústrias leves e o centro logístico se instalem em seus territórios, enquanto empurram as moradias para a outra. Os agentes estatais em diferentes escalas apresentaram métodos especulativos de empreendedorismo que corroboram o contexto global de atuação do Estado explicitado na introdução. Porém, a precariedade no entorno da área do empreendimento não nos deixa esquecer as particularidades do território latino americano, quando apresenta os característicos cenários de desigualdade e pobreza do sul global. 


\section{REFERÊNCIAS}

EXAME. SP entrega menos de 1\% das moradias prometidas em PPP. Site Revista Exame. Disponível em https://exame.abril.com.br/brasil/sp-entrega-menos-de-1-das-moradiasprometidas-em-ppp/ . Acesso em 16 de abril 2019.

HARVEY, D. 17 contradições e o fim do capitalismo. São Paulo: Boitempo, 2016.

MENDONÇA, P. Três contradições das PPPs paulistas: da provisão habitacional aos negócios imobiliário-financeiros. XVII ENANPUR. São Paulo. 2017.

O'BRIEN, P; O'NEILL, P; TOMANEY, J (2018). Governing the 'ungovernable'? Financialisation and the governance of transport infrastructure in the London 'global city-region'. Progress in Planning, 2018. ISSN 0305-9006. https://doi.org/10.1016/j.progress.2018.02.001.

O'BRIEN, P; O'NEILLI, P; PIKE, A. (2019). Funding, financing and governing urban infrastructures. Urban Studies. <https://doi.org/10.1177/0042098018824014/> Acesso em 10 de abril de 2019.

O Estado de São Paulo. A melhor esquina do País. 03 de julho de 2017. Disponível em: <http://patrocinados.estadao.com.br/cdhu/2017/07/03/a-melhor-esquina-do-pais/. . Acesso em 19 de abril de 2019.

SÃO PAULO. Ata da $41^{a}$ Reunião Ordinária do Conselho Gestor do Programa Estadual de Parcerias Público-Privadas. São Paulo: Diário Oficial do Estado de São Paulo, v. 121, n. 242, 27.12. 2011.

Edital de Chamamento Público 01-2015. São Paulo: Diário Oficial do Estado de São Paulo, v. 125, n.151. 15.08.2015.

. Ata da $72^{a}$ Reunião Ordinária do Conselho Gestor do Programa Estadual de Parcerias Público-Privadas. Diário Oficial do Estado de São Paulo, v.126, n.170. p.3, DOE 09/09/2016.

Ata da $73^{a}$ Reunião Ordinária do Conselho Gestor do Programa Estadual de Parcerias Público-Privadas. Diário Oficial do Estado de São Paulo, v.127, n.10. p.21, DOE $14 / 01 / 2017$

. Edital da PPP Habitacional - Nova Cidade Albor, Concorrência Internacional

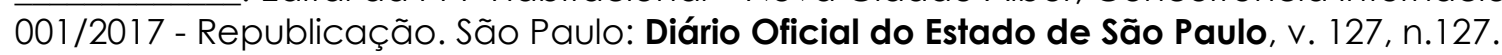
08.07.2017

. Ata $79^{a}$ Reunião Ordinária CGPPP. São Paulo: Diário Oficial do Estado de São Paulo, v. 128, n.35. 12.12.2017.

. Ata $13^{a}$ Reunião Extraordinária CGPPP. São Paulo: Diário Oficial do Estado de São Paulo, v.128, n.67. 12.04.2018

PREFEITURA DE ARUJÁ. Prefeitura apresenta reivindicações sobre PPP. Site official da Prefeitura de Arujá. Disponível em http://www.prefeituradearuja.sp.gov.br/notice.php?ld=4720. Acesso em 15 de abril de 2019.

SAVINI, F; AALBERS, M. B. (2016). The de-contextualisation of land use planning through financialisation: Urban redevelopment in Milan. European Urban and Regional Studies, 23(4), 878-894. <https://doi.org/10.1177/0969776415585887>. Acesso em 10 de março de 2019.

WEBER, R (2010) Selling city futures: the financialization of urban redevelopment policy. Economic Geography 86(3): 251-274. 